\title{
Sorption of Lead(II) ions from Aqueous Solution by Fabricated Magneto responsive CNT-IPSF/ $\mathrm{Fe}_{3} \mathrm{O}_{4}$ Nanocomposites
}

\author{
Shisia K. Silvanus ${ }^{1}$ and Andala M. Dickson ${ }^{2}$ \\ ${ }^{1}$ Departmentof Chemistry, Kenyatta University, Nairobi, \\ ${ }^{2}$ Departmentof Chemistry, MultiMedia University, Nairobi, Kenya
}

\begin{abstract}
Rapid industrial development associatedwith production of toxic wastes, especially heavy metals, has led to anurgent need of creating new sorption materials to remove these wastes from water supplies. This study aimed atdetermining the effectiveness of as-prepared CNT-IPSF/Fe ${ }_{3} \mathrm{O}_{4}$ nanocomposites in removal of lead(II) ionsfrom contaminated water. Carbon nanotubes prepared by CVD exhibited fine threads with average internal diameters of 40-50 nm while magnetite silica NPs had cubic spinel structure; due to the strongest reflection from the (311) plane. The silica coated magnetite had magnetization value of $2.5 \mathrm{emu} / \mathrm{g}$ while the polysulfonecontributed towards well packed and uniform structure depicting higher surface area suitable in adsorption studies. The magnetite silica NPs had very intense peaks, indicating the ultra-fine nature and small crystallite size of the particles. The peaks indexed as planes (220), (311), (400), (422), (511) and (440) corresponded to a cubic unit cell, characteristic of a cubic spinel structure while crystallite size measurements were determined as $22.4 \mathrm{~nm}$ from the strongest reflection of the (311) peak, using the Scherrer approximation. Optimization of parameters for $\mathrm{Pb}(\mathrm{II})$ ions removal gave optimum conditions of adsorbent dose $(0.05 \mathrm{~g})$, contact time (60 mins) and $\mathrm{pH} 5$ which were set constant in further analysis. Kinetics for adsorption of $\mathrm{Pb}$ (II) ions fitted well with pseudo second order model with highest correlation coefficient values of $>0.9$ while the adsorption process gave best fit with Freundlich isotherms.Desorption efficiencies (\%) for Pb(II) ions of above $50 \%$ confirms the reliability of the desorption test in the reusability of the magnetoresponsive CNT$I P S F / F_{3} \mathrm{O}_{4}$ nanocomposite fabricated. Desorption of the $\mathrm{Pb}(\mathrm{II})$ ions using $\mathrm{HNO}_{3}$ made the developed adsorbent a viable alternative to the common adsorbents available for treatment of wastewater with heavy metal ions. The nanocomposites showed $69 \%$ for $\mathrm{Pb}(\mathrm{II})$ ions removal from wastewater compared to $54 \% \mathrm{~Pb}(\mathrm{II})$ ions removal for activated carbon used as standard adsorbent.
\end{abstract}

Keywords: adsorption, desorption, carbon nanotubes, magnetoresponsive, nanoparticles, nanocomposites, reliability, solubility

\section{Introduction}

Heavy metals represent a large class of pollutants responsible for the pollution of many potential drinking water sources around the world[1]. The removal of heavy metals from wastewater is important for the environmental protection and human health[2]. Several processes such as chemical precipitation, reverse osmosis, electrolytic recovery, ion exchange or adsorption have been developed and usedover the years to remove metal ions[3]. Nanoparticles are fast emerging as potent candidates for water treatment in place of conventional technologies which, notwithstanding their efficacy, are often very expensive and time consuming [4]. Low cost of adsorbents, simplicity and high removal efficiency are few advantages of the adsorption method [5]. In order to make this method more environment friendly and economical, regeneration of adsorbent is very important aspect.

The need of recovery and regeneration depends on cost of the adsorbent and its regeneration[6]. The aim of this study was to investigate the effects of different factors on the adsorption properties of lead(II) ions by as-prepared CNT-IPSF/ $/ \mathrm{Fe}_{3} \mathrm{O}_{4}$ nanocomposites, which will help to understand adsorption mechanism for other heavy metals. Lead is chosen as a model metal ion, which has been identified as one of the most toxic heavy metals and is included on the US Environmental Protection Agency (USEPA) list of priority pollutants. In this paper, adsorption features of as-prepared CNT-IPSF/ $\mathrm{Fe}_{3} \mathrm{O}_{4}$ nanocompositeswere investigated as a function of $\mathrm{pH}$, adsorbent dose, initial $\mathrm{Pb}$ (II) concentrations and co-existing ions. The reliability of the nanocomposite was investigated using desorption test on removal of the adsorbed $\mathrm{Pb}$ (II) ions from the nanocomposites.

\section{Experimental Stage \\ 2.1 Fabrication and characterization of CNT-IPSF/Fe ${ }_{3} \mathrm{O}_{4}$ nanocomposites}

A continuous chemical vapour deposition (CVD) of acetylene was used to produce CNTs at temperatures of $600{ }^{\circ} \mathrm{C}$ as outlined in previous studies [7] and were characterized using SEM, EDAX and TEM.Magnetic $\mathrm{Fe}_{3} \mathrm{O}_{4}$ particles were prepared via solvothermal reaction according to the method previously reported [8] and characterized using UV-Vis and SEM techniques. Magnetite microspheres were coated with 
Sorption of Lead(II) ions from Aqueous Solution by Fabricated Magnetoresponsive CNT..

silica by sol-gel approach [9] by slow addition of $50 \mu \mathrm{L}$ tetraethyl orthosilicate (TEOS). Structural and particle sizewere determined by X-ray diffractometer (Shimadzu, XRD-6000) equipped with CuK $\alpha$ radiation source using $\mathrm{Ni}$ as filter at setting of $30 \mathrm{kV} / 30 \mathrm{mAin}$ the angular range $10 \leq 2 \theta \leq 90^{\circ}$ with a scanning speed of $0.02^{\circ} / \mathrm{s}$ and a step time of $3 \mathrm{~s}$. The magnetic properties of the prepared magnetite- silica NPs were determined by SQUID magnetometer. About $0.3 \mathrm{~g}$ of magnetite silica NPs were added to CNT-PSF polymer solutions, ultrasonicated for 1 hour and the CNT-IPSF/ $/ \mathrm{Fe}_{3} \mathrm{O}_{4}$ solutions were immediately cast onto a glass plate with the aid of a casting blade to form CNT-IPSF/ $/ \mathrm{Fe}_{3} \mathrm{O}_{4}$ nanocomposites.

\subsection{Removal of $\mathrm{Pb}(\mathrm{II})$ ions by fabricated $\mathrm{CNT}-\mathrm{IPSF} / \mathrm{Fe}_{3} \mathrm{O}_{4}$ nanocomposites \\ 2.2.1 Chemicals}

All chemicals used in this study were of analytical grade obtained from Aldrich sigma Analytical Instruments $\mathrm{Co}$. Ltd. $\mathrm{Pb}$ (II) ions solutions of different concentrations were obtained by diluting the stock solution. To adjust the $\mathrm{pH}, 0.1 \mathrm{~mol} / \mathrm{L} \mathrm{HNO}_{3}$ and $\mathrm{NaOH}$ solutions were used. The effect of cationic ions $\left(\mathrm{Zn}^{2+}\right.$, $\left.\mathrm{Cu}^{2+}, \mathrm{Cd}^{2+}\right)$ and anion/ ligands $\left(\mathrm{NO}_{3}{ }^{-}, \mathrm{NH}_{3}\right.$ and EDTA) on adsorption was studied. The regeneration studies of nanocompositeswere also done using varying concentrations of $\mathrm{Pb}(\mathrm{II})$ ions.

\subsubsection{Optimization of adsorption parameters}

\subsubsection{Determination of $\mathrm{pH}_{p z c}$}

Molar solutions of $\mathrm{HNO}_{3}$ and $\mathrm{NaOH}$ were mixed in six different vials at varied proportions to adjust the initial $\mathrm{pH}(\mathrm{pHi})$ values to $2,4,6,8,10$, and $12.0 .05 \mathrm{~g}$ of the adsorbent was added to each solution in the ratio of 1:5 w/v and shaken on an orbital platform shaker at $120 \mathrm{rpm}$ for $24 \mathrm{~h}$. The resulting solutions were left to settle for $5 \mathrm{~min}$ before the final $\mathrm{pH}$ (pHf) was measured. From a plot of pHf against pHi, the pHpzc was obtained as the plateau along the pHi axis.

\subsubsection{Effect of Adsorbent Dose}

$50 \mathrm{ml}$ aliquot solutions having initial concentration of $2 \mathrm{mg} / \mathrm{L}$ and $4 \mathrm{mg} / \mathrm{L}$ of the $\mathrm{Pb}^{2+}$ ions solutions were placed in two sets of conical flasks. Each of the adsorbent masses $(0.02 \mathrm{~g}, 0.04 \mathrm{~g}, 0.06 \mathrm{~g}, 0.08 \mathrm{~g}, 0.1 \mathrm{~g}$, and $0.12 \mathrm{~g})$ was added to each set of stoppered conical flasks and agitated $(120 \mathrm{rpm})$ for $60 \mathrm{~min}$ using an orbital platform shaker, after which they were left to equilibrate for $2 \mathrm{~h}$. This was followed by centrifugation to separate the bulk sorbent from the solution (before filtering) prior to subsequent analysis. At the end of the time, the mixtures were filtered and the $\mathrm{Pb}$ (II) ions concentrations in the filtrates were determined by an air acetylene flame atomic absorption spectrophotometer (UNICAM SOLAAR 32). Ten runs were conducted for each adsorbent dosage.

\subsubsection{Effect of Contact Time}

The effect of time on the interaction of the adsorbent with the $\mathrm{Pb}^{2+}$ ions was performed at optimum pH5. The adsorption studies were carried out by adding $0.05 \mathrm{~g}$ of adsorbent into two sets of conical flasks each containing $50 \mathrm{ml}$ of $2 \mathrm{mg} / \mathrm{L}$ and $4 \mathrm{mg} / \mathrm{L} \mathrm{Pb}(\mathrm{II})$ ions solutions in water bath shaker. The contact time for adsorption was varied at 10,20,30,60 90, 120 and 240 minsof agitation and immediately centrifuged for 15 min. Then, the concentrations of the $\mathrm{Pb}$ (II) ions in the supernatants were measured by an air acetylene flame atomic absorption spectrophotometer (UNICAM SOLAAR 32). All the experiments were carried out on 10 samples.

\subsubsection{Effect of $\mathrm{pH}$ on $\mathrm{Pb}(\mathrm{II})$ Adsorption}

A series of experiments, with $50 \mathrm{ml}$ aliquots standards of $2 \mathrm{mg} / \mathrm{L}$ and $4 \mathrm{mg} / \mathrm{L} \mathrm{Pb}$ (II) solutions in two sets of conical flasks were conducted under different $\mathrm{pH}$ The $\mathrm{pH}$ was first adjusted to a designed value, from 1.0 to 7.0 with $0.1 \mathrm{M} \mathrm{HNO}_{3}$ or $0.1 \mathrm{M} \mathrm{NaOH}$. Then it was adjusted hourly and maintained steadily throughout the experiment. This was to avoid the possible precipitation of target cations as hydroxides. About $0.05 \mathrm{~g}$ of the adsorbent was added to each flask (stoppered $100 \mathrm{~mL}$ flasks) and agitated using an orbital platform shaker (120 $\mathrm{rpm}$ ) for 60 minutes (optimum contact time) at $25{ }^{\circ} \mathrm{C}$, after which they were left to equilibrate for $2 \mathrm{~h}$. This was followed by centrifugation to separate the bulk sorbent from the solution (before filtering) prior to subsequent analysis. The suspensions were filtered and the concentration of $\mathrm{Pb}^{2+}$ ions in the filtrates was determined using an air acetylene atomic absorption spectrophotometer (UNICAM SOLAAR 32).

\subsubsection{Determining Adsorption Kinetics Model for Pb(II) Adsorption onto Adsorbent}

The adsorption studies were carried out by adding $0.05 \mathrm{~g}$ each of CNT-IPSF/Fe ${ }_{3} \mathrm{O}_{4}$ nanocompositesand activated carbon adsorbent into two sets of conical flasks containing $50 \mathrm{ml}$ of $2 \mathrm{mg} / \mathrm{L} \mathrm{Pb}$ (II) ions solutions in water bath shaker. The contact time for adsorption was varied from 10 to $250 \mathrm{~min}$ and immediately centrifuged for $15 \mathrm{~min}$. Then, the concentrations of the $\mathrm{Pb}$ (II) ions in the supernatants were measured after 10, 20, 30, 60 90, 
Sorption of Lead(II) ions from Aqueous Solution by Fabricated Magnetoresponsive CNT..

120,180 and 250 mins of agitation by an air acetylene flame atomic absorption spectrophotometer at $248.3 \mathrm{~nm}$. All of the adsorption experiments were conducted in triplicate, and the average results are reported.

\subsubsection{Determining Adsorption Isotherms Model for Pb(II) Adsorption onto Adsorbent}

The initial concentration of the metal ions was varied between 2 and $12 \mathrm{mg} / \mathrm{L}$. A known weight $(0.05$ g) of the CNT-IPSF/Fe ${ }_{3} \mathrm{O}_{4}$ nanocomposites was shaken with $50 \mathrm{ml}$ of $\mathrm{Pb}$ (II) ion standards at pH 5 for 60 mins (optimized contact time) at $25{ }^{\circ} \mathrm{C}$ on a rotatory shaker to ensure removal equilibrium was reached. The adsorbent was removed after centrifugation $(10 \mathrm{~min})$ for easy filtration. Finally, the $\mathrm{Pb}^{2+}$ ions concentrations were determined by AAS. All of the adsorption experiments were conducted in triplicate, and the average results are reported. For control experiments, $0.05 \mathrm{~g}$ of standard adsorbent of activated carbon was put into plastic bottles with $50 \mathrm{ml}$ of 2, 4, 6, 8, 10 and $12 \mathrm{mg} / \mathrm{L}$ of $\mathrm{Pb}(\mathrm{II})$ solutions at $25{ }^{\circ} \mathrm{C}$ and $\mathrm{pH} 5$, and mixture shaken for 60 minutes of contact time. The mixtures were treated in similar way and residual $\mathrm{Pb}$ (II) determined by AAS. The adsorption data obtained were fitted to adsorption isotherms models.

\subsubsection{Effect of Counter Ions on Pb(II) Adsorption}

The effect of similar heavy metal ions and anionic ligands were studied by using $0.05 \mathrm{~g}$ CNTIPSF/ $/ \mathrm{Fe}_{3} \mathrm{O}_{4}$ nanocompositesin $2 \mathrm{mg} / \mathrm{L} \mathrm{Pb}$ (II) solution each spiked with respective cations $\left(\mathrm{Zn}^{2+}, \mathrm{Cu}^{2+}\right.$ and $\left.\mathrm{Cd}^{2+}\right)$ and anion/ ligands $\left(\mathrm{NO}_{3}{ }^{-}, \mathrm{NH}_{3}\right.$ and EDTA) of concentrations $1.0 \mathrm{mgl} / \mathrm{L}$. Blank samples without similar heavy metals and anionic ligands were used. Control experiment involved putting $0.05 \mathrm{~g}$ of activated carbon into plastic bottles with each $50 \mathrm{ml}$ of $2 \mathrm{mg} / \mathrm{L}$ of $\mathrm{Pb}(\mathrm{II})$ ions solution spiked with $\mathrm{Zn}^{2+}, \mathrm{Cu}^{2+}, \mathrm{Cd}^{2+}$ cations and $\mathrm{NO}_{3}^{-}$, $\mathrm{NH}_{3}$, EDTA at concentrations of $1 \mathrm{mg} / \mathrm{L}$.

\subsubsection{Application of CNT-IPSF/Fe ${ }_{3} \mathrm{O}_{4} \mathrm{Nanocomposite} \mathrm{in} \mathrm{Wastewater} \mathrm{Treatment}$ \\ 2.2.3.1 Wastewater Sampling}

Ten water samples containing industrial effluents of about one litre capacity were collected using a standard sampling technique [10].Care was taken to avoid contamination of the sample during sampling, handling and transport to the laboratory by using polyethylene bags as leaching and adsorption are minimal. Sample containers were cleaned and where reagents were added during the preservation step, a sample of the added reagents was also submitted for analysis as a reagent blank. The samples were immediately cooled (on ice) before further analysis.

\subsubsection{Application of CNT-IPSF/Fe ${ }_{3} \mathrm{O}_{4}$ Nanocomposite to $\mathrm{Pb}(\mathrm{II})$ ions Removal from Wastewater}

Prior to sorption and desorption experiments, the water samples were filtered and portions of it analyzed for initial concentrations of $\mathrm{Pb}$ (II) ions using AAS. The rest of water samples were stored at $4{ }^{\circ} \mathrm{C}$ in a refrigerator for further analysis. $50 \mathrm{~mL}$ each of the effluent samples whose $\mathrm{pH}$ had been adjusted to 5 was gently agitated with $0.05 \mathrm{~g}$ of as-prepared adsorbent on a rotatory shaker $(120 \mathrm{rpm})$ for $1 \mathrm{~h}$ at $25{ }^{\circ} \mathrm{C}$. Before AAS analysis, the mixtures were immediately filtered through No 1 paper filter. The adsorbent with adsorbed lead were washed three times using $0.1 \mathrm{M} \mathrm{HNO}_{3}$. All the experiments were carried out on 10 samples. Control experiments used $0.05 \mathrm{~g}$ standard adsorbent (activated carbon) on $50 \mathrm{ml}$ effluent samples and agitated at fixed temperature $25^{\circ} \mathrm{C}$ for one hour and at $120 \mathrm{rpm}$. The standard adsorbent was also washed three in $0.1 \mathrm{M} \mathrm{HNO}_{3}$ before determining residual $\mathrm{Pb}(\mathrm{II})$ ions in the resultant filtrates. Comparison of their \% removal efficiencies was done to establish if the prepared adsorbent was more efficient than the standard adsorbent employed.

\subsubsection{Regeneration and Reusability Studies on Adsorbent Using Lead(II) ions \\ 2.2.4.1 Adsorption-Desorption Experiments for Pb(II) ions}

Desorption studies were carried out in order to determine the strength of the adsorption process and investigate the feasibility of its regeneration for reuse. Each of the $0.05 \mathrm{~g}$ adsorbent was continuously stirred with $50 \mathrm{ml}$ of $2 \mathrm{mg} / \mathrm{L} \mathrm{Pb}$ (II) solutions in plastic bottles to allow adsorption to take place. After filtration, each adsorbent with $\mathrm{Pb}(\mathrm{II})$ load was transferred to each conical flask containing $50 \mathrm{ml}$ desorption solvents of $\mathrm{H}_{2} \mathrm{O}$, $0.1 \mathrm{M} \mathrm{HNO}_{3}$, and $0.1 \mathrm{M}$ EDTA. The mixtures were shaken at $120 \mathrm{rpm}$ for $18 \mathrm{~h}$ followed by determination of the concentration of $\mathrm{Pb}(\mathrm{II})$ in the filtrates after desorption. The experiment was repeated using $0.05 \mathrm{~g}$ of standard activated carbon adsorbent into each of the plastic bottles (pools) containing $2 \mathrm{mg} / \mathrm{L} \mathrm{Pb}(\mathrm{II}$ ) ions solution and treated in the same manner as for prepared adsorbent. Ten sample portions were run for this experiment and the $\mathrm{Pb}(\mathrm{II})$ ions in filtrates was determined by AAS.

\subsubsection{Reusability of CNT-IPSF/Fe ${ }_{3} \mathrm{O}_{4} \mathrm{Nanocomposite} \mathrm{for} \mathrm{Pb}(\mathrm{II})$ Ions}

To investigate the reusability of the adsorbent, desorption and regeneration of Pb-loaded CNT$\mathrm{IPSF} / \mathrm{Fe}_{3} \mathrm{O}_{4}$ nanocomposites were also carried out. Adsorption desorption experiments were carried by agitating $0.05 \mathrm{~g}$ of prepared adsorbent in varying $\mathrm{Pb}^{2+}$ ions concentrations $(1,2.4,6,8$ and $10 \mathrm{mg} / \mathrm{L})$. After adsorption 
process, the adsorbent was separated magnetically and washed several times with deionized water to remove any unadsorbed $\mathrm{Pb}(\mathrm{II})$ ions and then desorption studies were performed by mixing resultant $\mathrm{Pb}$-loaded adsorbent with $20 \mathrm{~mL}$ of $0.10 \mathrm{M} \mathrm{HNO}_{3}$ in water shaker bath for $1 \mathrm{~h}$. Then the adsorbent was separated magnetically and the dried adsorbent was added to the solution of fresh $\mathrm{Pb}$ (II) ions solutions and after stirring with mechanical stirrer, the spent adsorbent was separated from the solution. Then Pb-loaded adsorbent was mixed with $20 \mathrm{~mL}$ of $0.10 \mathrm{M} \mathrm{HNO}_{3}$, shaken and separated from the solution. The process was repeated three times to investigate reliability of the adsorption test for possible reuse of the adsorbent as per the equation (1):

$\%$ Desorption Efficiency $=\frac{\text { Amount of metal ions desorbed }}{\text { Amount of metal ions adsorbed }} x 100 \ldots \ldots \ldots \ldots \ldots \ldots \ldots \ldots \ldots \ldots \ldots \ldots \ldots \ldots \ldots \ldots$

\subsubsection{Solubility Studies on CNT-IPSF/ $\mathrm{Fe}_{3} \mathrm{O}_{4} \mathrm{Nanocomposite}$}

Approximately $0.05 \mathrm{~g}$ of the adsorbent was added to $50 \mathrm{~mL}$ deionized water and conditioned at the $\mathrm{pH}$ values of $2,4,7,9$, and 12 [11] and thoroughly mixed on a vortex, followed by equilibration for $24 \mathrm{~h}$ at ambient temperature. The resulting mixture settled down, and with careful suctioning the remaining solid material obtained was then dried at $100{ }^{\circ} \mathrm{C}$ to a constant mass. Solubility was determined as the difference between the initial mass of the adsobent $\left(\mathrm{m}_{\mathrm{i}}\right)$ and that of the residue $\left(\mathrm{m}_{\mathrm{f}}\right)$, as given by the equation $(2)$ :

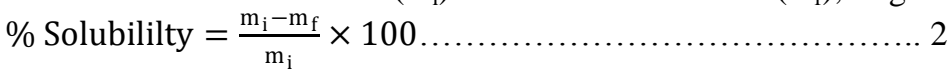

\section{Results}

\subsection{Fabrication of magnetic CNT-IPSF nanocomposites}

The HRSEM of prepared CNTs contain thin-like strings characteristic of CNTs (Fig. 1a). However, the SEM image shown in Fig. 1b shows the formation of magnetite-silica nanoparticles which were monodispersed in the presence of TEOS. Other studies found that with the increase of silica layer thickness, silica-coated magnetite particles become more monodispersed as a result of the reduction in the relatively size distribution and uniform silica-coated magnetite particles were formed [12, 13]. The XRD diffraction pattern in Fig.1c shows a complete range of allowed electron transitions in our synthesized magnetite NPs with the most intense peak given by $\mathrm{D}$-value of 311 from the Bragg's law: $n \lambda=2 \mathrm{~d} \sin \theta$. The sample show very intense peaks, indicating the ultra-fine nature and small crystallite size of the particles as shown by other studies [14]. Crystallite size measurements were determined as $22.4 \mathrm{~nm}$ from the strongest reflection of the (311) peak, using the Scherrer approximation, which assumed the small crystallite size to be the cause of line broadening $[15,16]$.

The hysteresis loop of our synthesized $\mathrm{Fe}_{3} \mathrm{O}_{4}-\mathrm{SiO}_{2} \mathrm{NPs}$ at room temperature is showed in Fig.1d. From the magnetization behavior, the magnetization curve is without hysteresis. It can also be seen that the saturation magnetization (Ms) of the $\mathrm{Fe}_{3} \mathrm{O}_{4}-\mathrm{SiO}_{2} \mathrm{NPs}$ increase from 1.50 to $2.0 \mathrm{emu} / \mathrm{g}$. This confirms that the as-prepared magnetite-silica NPs are characteristic of superparamagnetic properties. These particles also have zero coercivityand have no hysteresis. This study shows an external field response which follows a sigmoidal curve, a characteristic property of superparamagnetic NPs [17].

From the SEM image of fabricated CNT-IPSF/Fe ${ }_{3} \mathrm{O}_{4}$ nanocomposites in Fig.1eshows a well packed and uniform structure depicting higher surface area suitable adsorption studies. Also a large quantity of dispersive NPs having moderately uniform and cubic structure can be observed. Chemical analysis spectrum from EDAX (Fig. 1f) confirmed the presence of $\mathrm{Fe}$ and $\mathrm{O}$ elements, with a stoichiometry $\mathrm{Fe}_{3} \mathrm{O}_{4}$ phase $\mathrm{C}$ and $\mathrm{S}$ are candidates for CNTs and Infused polysulfone respectively. 
(a)
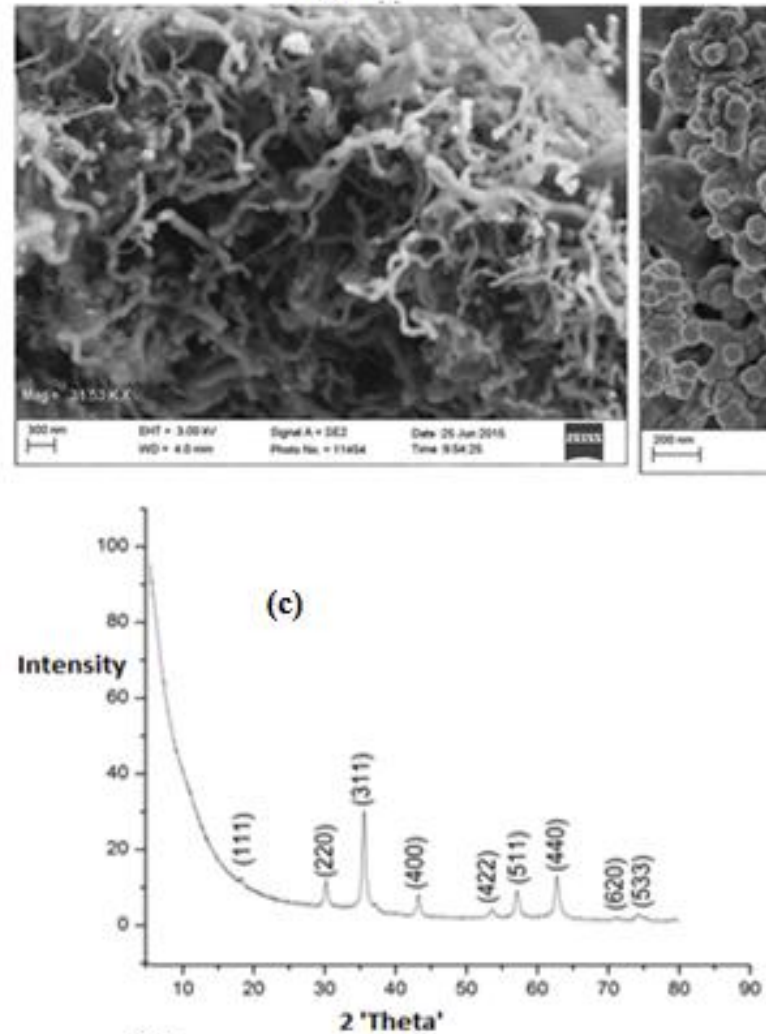

(b)

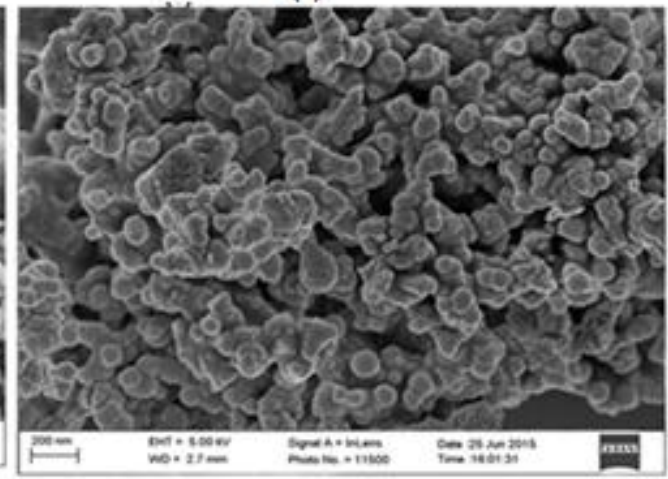

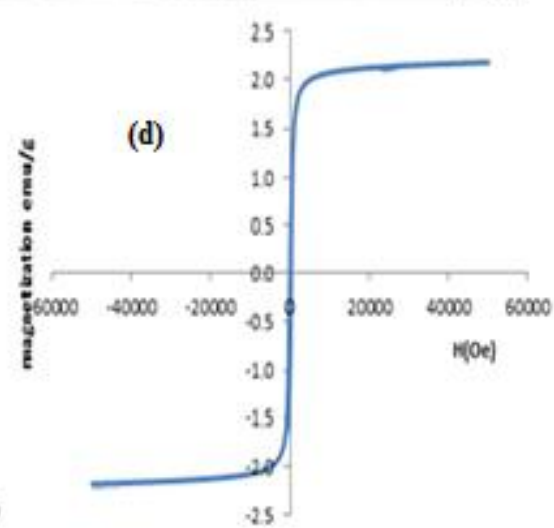

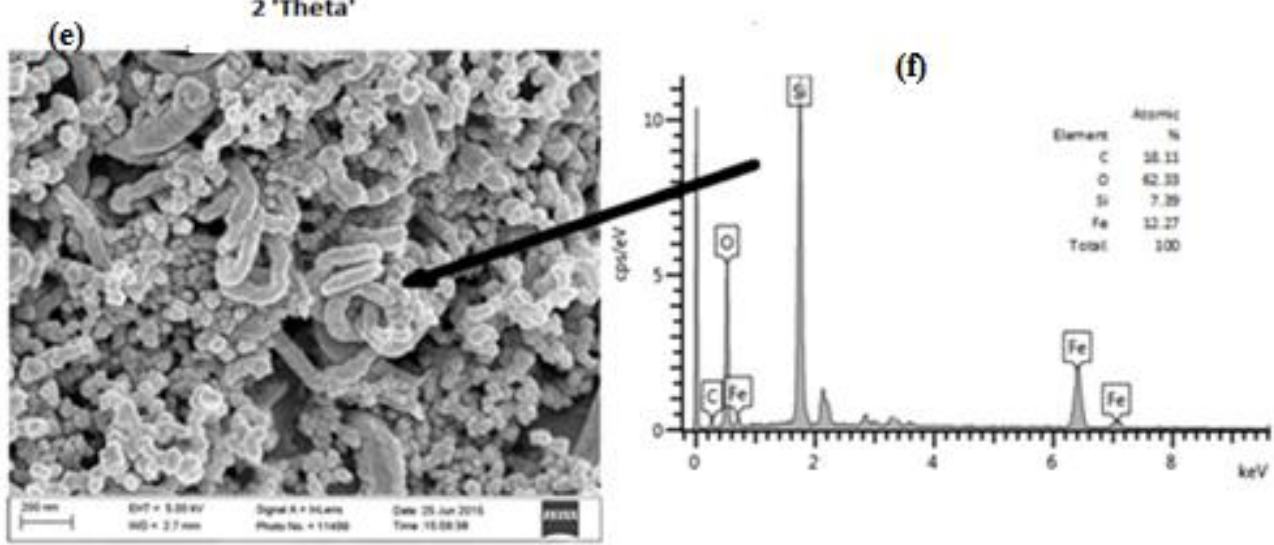

Figure (I) Characterization of products

\subsection{Efficiency of Magnetic CNT-IPSF Nanocomposite in Removal of Lead (Ii) Ions from Wastewater 3.2.1 Optimization of Factors}

The $\mathrm{pH}_{\mathrm{pzc}}$ is used to investigate whether the surfaces of adsorbent are either positively or negatively charged depending on their interaction with the $\mathrm{pH}$ of the solution in contact. From the $\mathrm{pH}_{\mathrm{pzc}}$ curve of the sample, the $\mathrm{pH}_{\mathrm{pzc}}$ value was found to be around 4.5 (Fig. 2a). This result reveals the possible presence of acidic oxygen-bearing surface functionalities, such as $-\mathrm{COOH}$ and $-\mathrm{OH}$ groups. Essentially, at $\mathrm{pH}_{\mathrm{pzc}}$ values 6-8, these groups would become negative via deprotonation, creating vacant sites for the binding of positively charged metal ions. Considering that the MWCNTs sample had already been functionalized with mineral acid $\mathrm{HNO}_{3}$ during purification stage, exhibiting such groups in significant quantities could be more economical. It is therefore expected that the adsorbent would bind to the $\mathrm{Pb}^{2+}$ ions through electrostatic interaction or by cation exchange. Hence, a high removal capacity (for the metal ions) from the solution is expected at $\mathrm{pH}$ values higher than pHpzc. Our results are in agreement with the reported point of zero charge of polysaccharide extract at 4.4 [11]. High removal capacity from the solution is expected at $\mathrm{pH}$ values greater than $\mathrm{pHpzc}$. Hence all the adsorption experiments were conducted at $\mathrm{pH} 5$. 

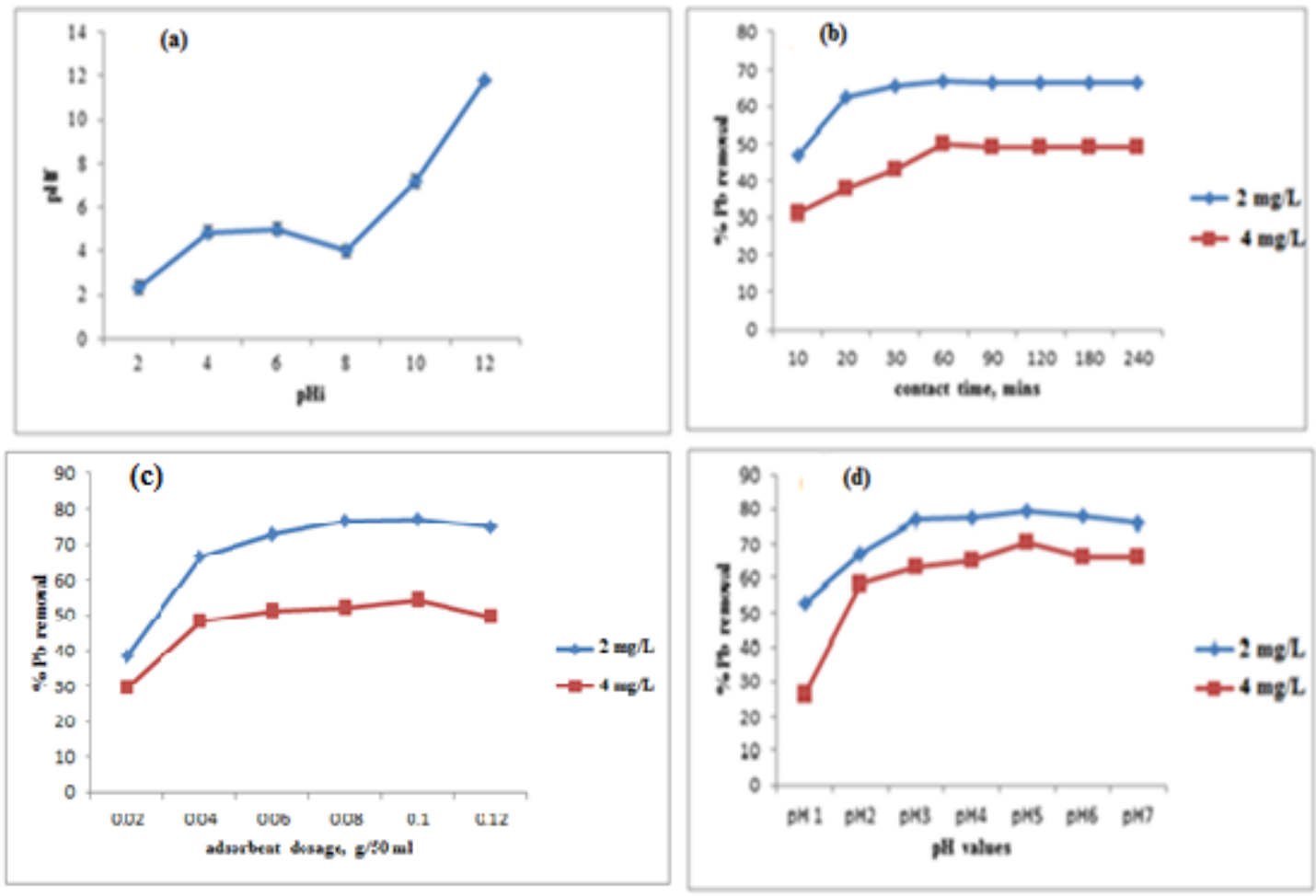

Figure (1) Optimization of Factors

The adsorption of lead ion on adsorbent was studied by varying the adsorbent dosage from $0.02-0.12 \mathrm{~g}$ at lead ion concentration ( $2 \mathrm{mg} / \mathrm{L}$ and $4 \mathrm{mg} / \mathrm{L}$ ) while keeping other operational parameters constant: $\mathrm{pH} 5$, shaking speed $120 \mathrm{rpm}$ and temperature $25{ }^{\circ} \mathrm{C}$ (Fig. 2b). The initial rapid increase observed could be due to the increased availability of binding sites and surface area for easy adsorption of $\mathrm{Pb}(\mathrm{II})$ ions until equilibrium was reached [18]. The results showed an exponential increase in the removal of $\mathrm{Pb}^{2+}$ as the dosage was increased at constant $\mathrm{Pb}^{2+}$ ions concentrations ( 2 and $4 \mathrm{mg} / \mathrm{L}$ ). This is because increasing the amount of the sorbent provides a larger surface area (more sorption sites) for binding metal ions.

This study investigated the removal efficiency of $\mathrm{Pb}^{2+}$ ions as a function of contact time between 10 and $240 \mathrm{~min}$ (Fig. 2c). There was maximum removal of $\mathrm{Pb}^{2+}$ ions of $67 \%(2 \mathrm{mg} / \mathrm{L})$ and $50 \%(4 \mathrm{mg} / \mathrm{L})$ at 60 mins of contact time indicating that equilibrium condition had been reached. This shows that the remaining empty sites on the adsorbent had been occupied leading to repulsive forces between adsorbed lead(II) ion on the adsorbent and those in the aqueous phase [19].

The effects of solution $\mathrm{pH}$ on lead(II) removal by the adsorbent was studied in the $\mathrm{pH}$ range $1-7$ at contact time of 60 mins and all measurements were made at room temperature for initial $\mathrm{Pb}$ (II) concentrations of 2 and $4 \mathrm{mg} / \mathrm{L}$ (Fig.2d). The increase in the removal of $\mathrm{Pb}^{2+}$ ions with the $\mathrm{pH}$ could be due to the fact that as the $\mathrm{pH}$ increases, the $\mathrm{H}^{+}$ions are desorbed from the functional groups. Hence, the adsorbent's surface becomes more negative, thereby increasing the attraction of metal ions to the free sites of the adsorbent, resulting in high removal efficiencies. The adsorbent's adsorption efficiencies toward $\mathrm{Pb}^{2+}$ ions were optimized by $79 \%$ and 70 $\%$ at $\mathrm{pH} 5$ for 2 and $4 \mathrm{mg} / \mathrm{L} \mathrm{Pb}^{2+}$ ions concentrations respectively.

\subsubsection{Adsorption Kinetics Modeling for Pb(II) Adsorption onto Adsorbent}

The experimental values for adsorption of lead ion involved agitating $0.05 \mathrm{~g} / 50 \mathrm{~mL}$ prepared (CNT$\mathrm{IPSF} / \mathrm{Fe}_{3} \mathrm{O}_{4}$ ) and standard (activated carbon) adsorbents at the $\mathrm{Pb}(\mathrm{II})$ ion concentrations of $2 \mathrm{mg} / \mathrm{L}$ and contact times of 10-250 mins, and pH5. In this study, two kinetic models were studied to describe the kinetics of adsorption. These include Pseudo First Order (equation 3) and Pseudo Second order (equation 4) [20].

$\log (Q e-Q t)=\log Q e-\frac{K_{1 p}}{2.303} t$

$\frac{t}{Q_{t}}=\frac{1}{K_{2 p} Q_{e}^{2}}+\frac{1}{Q_{e}} .$.

The kinetic parameters are shown in Table (1): 
Sorption of Lead(II) ions from Aqueous Solution by Fabricated Magnetoresponsive CNT..

Table (1) Pseudo first and second order adsorption constants

\begin{tabular}{|c|c|c|c|}
\hline \multirow[t]{2}{*}{ Kinetics } & \multirow[t]{2}{*}{ Parameters } & \multicolumn{2}{|c|}{ Samples } \\
\hline & & Prepared (CNT-IPSF) & Standard (activated carbon) \\
\hline \multirow{3}{*}{$\begin{array}{l}\text { Pseudo } \\
\text { order }\end{array}$} & $\mathrm{q}_{\mathrm{e}}$ & 0.34 & 0.24 \\
\hline & $\mathrm{K}_{1 \mathrm{p}}$ & 0.0046 & 0.005 \\
\hline & $\mathrm{R}^{2}$ & 0.7348 & 0.1992 \\
\hline \multirow{2}{*}{$\begin{array}{l}\text { Pseudo } \\
\text { Order }\end{array}$} & $\mathrm{q}_{\mathrm{e}}$ & 0.38 & 0.43 \\
\hline & $\begin{array}{l}\mathrm{K}_{2 \mathrm{p}} \\
\mathrm{R}^{2}\end{array}$ & $\begin{array}{l}0.308 \\
09982\end{array}$ & $\begin{array}{l}0.28 \\
0.999\end{array}$ \\
\hline
\end{tabular}

From the above results, the kinetics of adsorption followed the pseudo-second-order model. This model gives the best- fit to experimental data for $\mathrm{Pb}$ (II) for the prepared and standard adsorbents studied in this study, which have highest correlation coefficient values of 0.9982 and 0.999 respectively for same initial $\mathrm{Pb}$ (II) ions concentration of $2 \mathrm{mg} / \mathrm{L}$. That means that the rate of occupation of adsorption sites is proportional to the square number of unoccupied sites, because the pseudo-second order model is based on a second order mechanism [21].

\subsubsection{Adsorption Isotherm Modeling for Pb(II) Adsorption onto Adsorbent}

The initial metal ion concentration provides an important force to overcome all mass transfer resistances of the metal ions between aqueous and solid phase (Aksu\&Akpinar, 2000). The subsequent removal of metal ions using a constant amount of adsorbent was examined at various concentrations in the range 2-12 $\mathrm{mg} / \mathrm{L}$. The adsorption isotherms data were fitted to both the Langmuir (equation 5) and Freundlich (equation 6) isotherm equations [22].

$\frac{C_{e}}{q_{e}}=\frac{1}{q_{m} \cdot b}+\frac{C_{e}}{q_{m}}$.

$\log q_{e}=\log K_{f}+\frac{1}{n} \log C_{e}$

According to the $\mathrm{R}^{2}$ for each sample in Table (2), both Langmuir and Freundlich models fitted the experimental data by linear analysis.

Table (2) Langmuir and Freundlich adsorption isotherm constant for adsorption of $\mathrm{Pb}$ (II) onto magnetic CNTIPSF adsorbent and activated carbon adsorbents

\begin{tabular}{llll}
\cline { 2 - 4 } Isotherms & Parameters & Samples & \\
& & Prepared (CNT-IPSF) & Standard (activated carbon) \\
\cline { 2 - 4 } Langmuir & $\mathrm{Q}_{\mathrm{m}}$ & 20.62 & 20.33 \\
& $\mathrm{~b}$ & 0.04 & 0.26 \\
& $\mathrm{R}^{2}$ & 0.9968 & 0.9942 \\
\cline { 2 - 4 } Freundlich & $\mathrm{Kf}$ & 1.13 & 2.09 \\
& $1 / \mathrm{n}$ & 0.8286 & 0.85 \\
& $\mathrm{n}$ & 1.21 & 1.24 \\
& $\mathrm{R}^{2}$ & 0.9969 & 0.9984 \\
\hline
\end{tabular}

The linear form of correlation coefficient value $\mathrm{R}^{2}=0.9968$ (prepared) and $\mathrm{R}^{2}=0.9942$ (standard) for Langmuir isotherm and $\mathrm{R}^{2}=0.9969$ (prepared) and $\mathrm{R}^{2}=0.9984$ (standard) for Freundlich can suggest that both isotherms provide a good result for the adsorption model of $\mathrm{Pb}$ (II) on the adsorbents. The Langmuir isotherm provides a good model for the adsorption process as indicated by the regression coefficient $\left(\mathrm{R}^{2}\right)$ ranging from 0.9968 to 0.9942 for prepared and standard adsorbents respectively. This indicates that the surface of the CNTIPSF/ $/ \mathrm{Fe}_{3} \mathrm{O}_{4}$ nanocomposite is uniform, all the adsorption sites are equivalent and the adsorbed lead molecules do not interact. At the maximum adsorption, only a monolayer is formed [23]. The values of $n=1.21$ for $\mathrm{CNT}$ IPSF/ $\mathrm{Fe}_{3} \mathrm{O}_{4}$ nanocomposite were between 1 and 10 representing beneficial adsorption [24]. The obtained values of $1 / \mathrm{n}$ are less than unity $(1 / \mathrm{n}=0.83)$ which is an indication that significant adsorption takes place at low metal ions concentrations.

\subsubsection{Effect of Counter Ions}

Industrial wastewater often contains other similar divalent cations such as $\mathrm{Zn}^{2+}, \mathrm{Cu}^{2+}$ and $\mathrm{Cd}^{2+}$, and $\mathrm{NO}_{3}{ }^{-}, \mathrm{NH}_{3}$ and EDTA [25], which may interfere with the uptake of $\mathrm{Pb}(\mathrm{II})$ ions by adsorbent. The effect of such cations and anion/ligands on adsorption was studied and the results are shown in Figure $3 \mathrm{a}$ and $3 \mathrm{~b}$ respectively. 
It can be seen that $1 \mathrm{mg} / \mathrm{L}$ of $\mathrm{Cu}^{2+}$ greatly reduced $\mathrm{Pb}(\mathrm{II})$ removal by a significant drop of about $2.08 \%$ on the standard adsorbent from when $1 \mathrm{mg} / \mathrm{L}$ of $\mathrm{Zn}^{2+}$ was used on standard adsorbent. The as-prepared adsorbent was not affected by any of the counter cations. Comparison of $\mathrm{Pb}$ (II) removal by both activated carbon (standard) and CNT-IPSF/ $\mathrm{Fe}_{3} \mathrm{O}_{4}$ (prepared) adsorbents revealed similar trend with EDTA significantly reducing $\mathrm{Pb}$ (II) removal by almost the same margin.
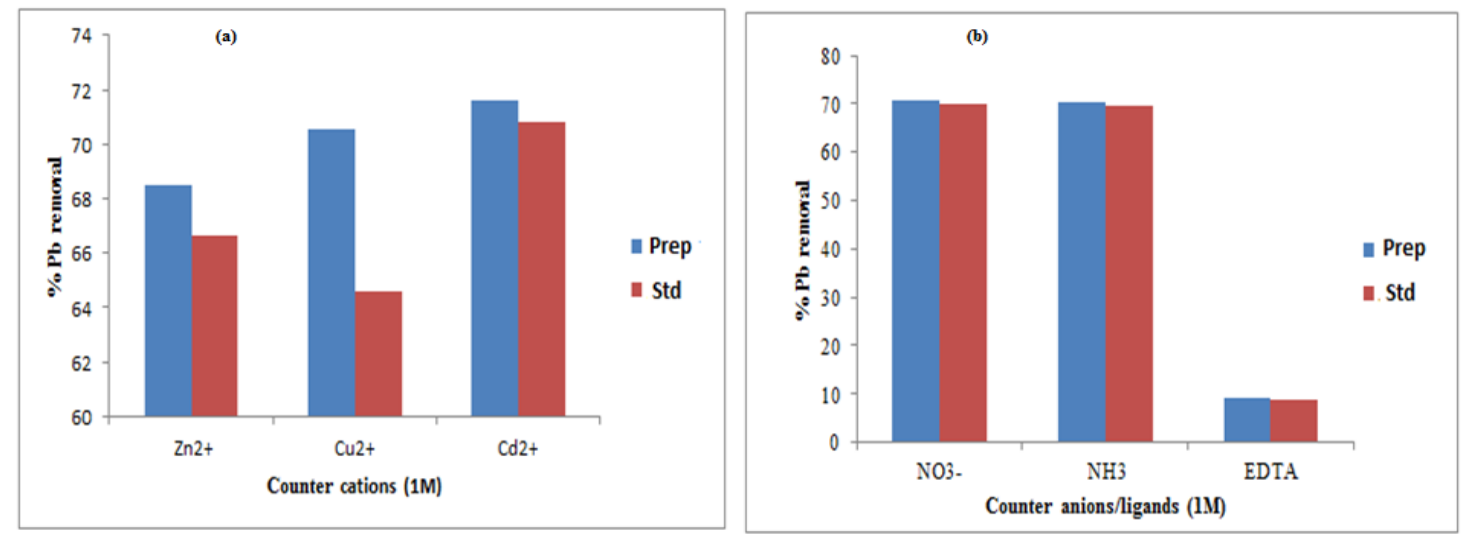

Figure (2) Application of CNT-IPSF/ $\mathrm{Fe}_{3} \mathrm{O}_{4}$ Nanocomposite in Wastewater Treatment

Application studies using polluted water samples with industrial effluent was carried out to determine the practicality of $\mathrm{CNT}-\mathrm{IPSF} / \mathrm{Fe}_{3} \mathrm{O}_{4}$ nanocomposites at optimum batch condition as shown in Figure 4

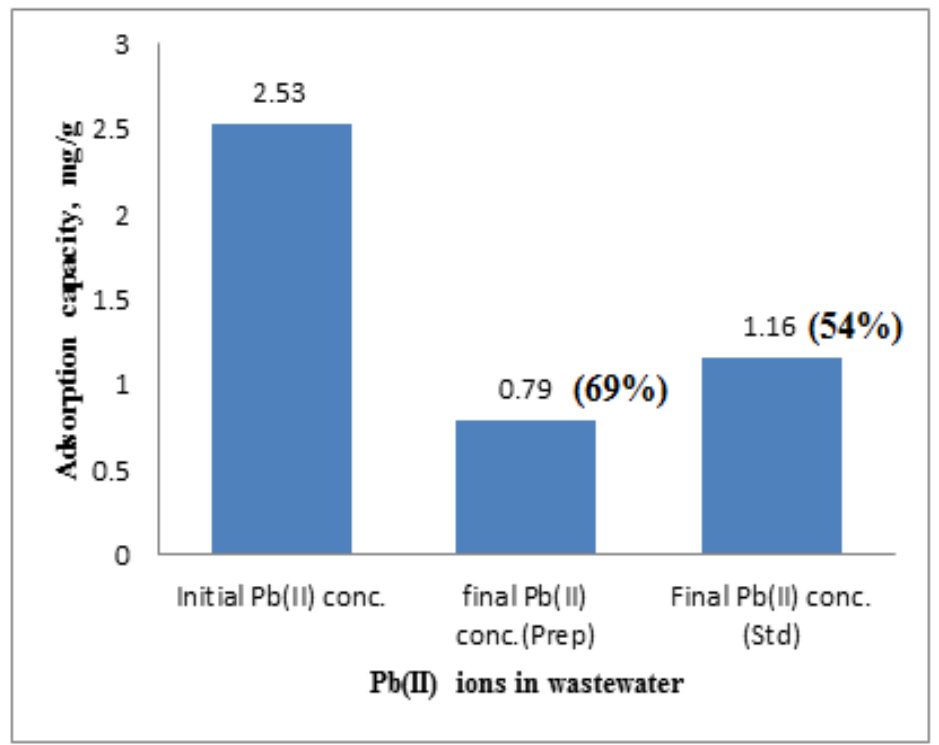

Figure (3) Industrial wastewater treatment

The prepared magnetic CNT-IPSF/ $/ \mathrm{Fe}_{3} \mathrm{O}_{4}$ nanomposites and activated carbon adsorbent reduced initial concentration of $\mathrm{Pb}$ (II) ions from $2.53 \mathrm{mg} / \mathrm{g}$ to 0.79 and $1.16 \mathrm{mg} / \mathrm{g}$ which translated into $69 \%$ and $54 \%$ respectively after three washing times with $\mathrm{HNO}_{3}$. This implies that the CNT-IPSF/Fe $\mathrm{O}_{4}$ nanocomposite has adsorbent particles with higher affinity for $\mathrm{Pb}^{2+}$ ions than those in activated carbon [26]. The ability of CNT$\mathrm{IPSF} / \mathrm{Fe}_{3} \mathrm{O}_{4}$ nanocomposite to remove $\mathrm{Pb}$ (II) ions from aqueous solutions could be attributed to its high magnetic response from single- and multi-core magnetic, and its tunable morphologies [27]. The prepared adsorbent was therefore more effective in the removal of $\mathrm{Pb}(\mathrm{II})$ ions from industry wastewater.

\subsection{Regeneration and Reusability of Magnetoresponsive CNT-IPSF/F $\mathrm{F}_{3} \mathrm{O}_{4} \mathrm{Nanocomposite}$ 3.3.1 Adsorption-Desorption Studies for Pb(II) ions}

This study was carried out to assess the most suitable desorbing agent [28] for eluting adsorbed lead(II) ion from the surface of prepared CNT-IPSF/ $\mathrm{Fe}_{3} \mathrm{O}_{4}$ nanocomposites and standard activated carbon adsorbent. The effects of de-ionized water, $0.1 \mathrm{M} \mathrm{HNO}_{3}$ and $0.1 \mathrm{M}$ EDTA solutions were tested for their ability to remove the adsorbed lead(II) ion from the surface of the adsorbents (Figure 5). From the results, it can be seen that $0.1 \mathrm{M}$ 
$\mathrm{HNO}_{3}(78 \%$ and $81 \%)$ and $0.1 \mathrm{M}$ EDTA $(77 \%$ and $76 \%)$ were equally more efficient than $\mathrm{H}_{2} \mathrm{O}(9.09 \%$ and $9.12 \%)$ solvent. The high desorption ability of EDTA in desorption studies could be due to the high value of the conditional formation constant of the complex $\mathrm{Pb}(\mathrm{II})$-EDTA $\left(\mathrm{K}_{\mathrm{f}}^{\prime}=3.55 \times 10^{11}\right)$ at $\mathrm{pH}$ 5.0, which favors the desorption of $\mathrm{Pb}(\mathrm{II})$ from the sorbent [29]. However, $\mathrm{HNO}_{3}$ acid desorption solvent was chosen for adsorptiondesorption studies during reusability test since Pb-EDTA complexes has shown limited adsorption at various $\mathrm{pH}$ values.

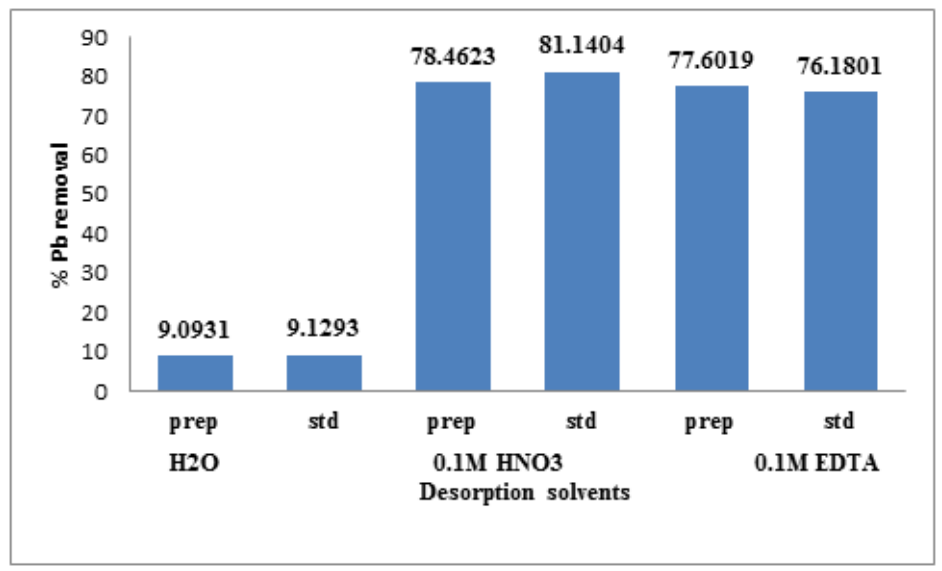

Figure (5) Comparing desorption abilities using different desorption solvents

\subsubsection{Reusability of CNT-IPSF/Fe ${ }_{3} \mathrm{O}_{4}$ Nanocomposite for $\mathrm{Pb}(\mathrm{II})$ Ions}

Desorption efficiencies (\%) were then carried out as a function of varying concentrations for $\mathrm{Pb}^{2+}$ ions solution $\left(1,2,4,6,8\right.$ and $10 \mathrm{mg} / \mathrm{L}$ ) on the prepared adsorbent using $\mathrm{HNO}_{3}$ as desorption solvent (Figure 6a). This desorption test, if reliable, could positively impact the subsequent utilization of sorbents, thus providing high chances of its reusability. Herein, the concentrations of $\mathrm{Pb}^{2+}$ ions were measured after equilibrium had been reached. The desorption efficiency (\% DE) was derived as the amount of adsorbed metal ions released from the sorbent's surface relative to the initially adsorbed on the adsorbent material before desorption using $\mathrm{HNO}_{3}$ (Figure 6b).
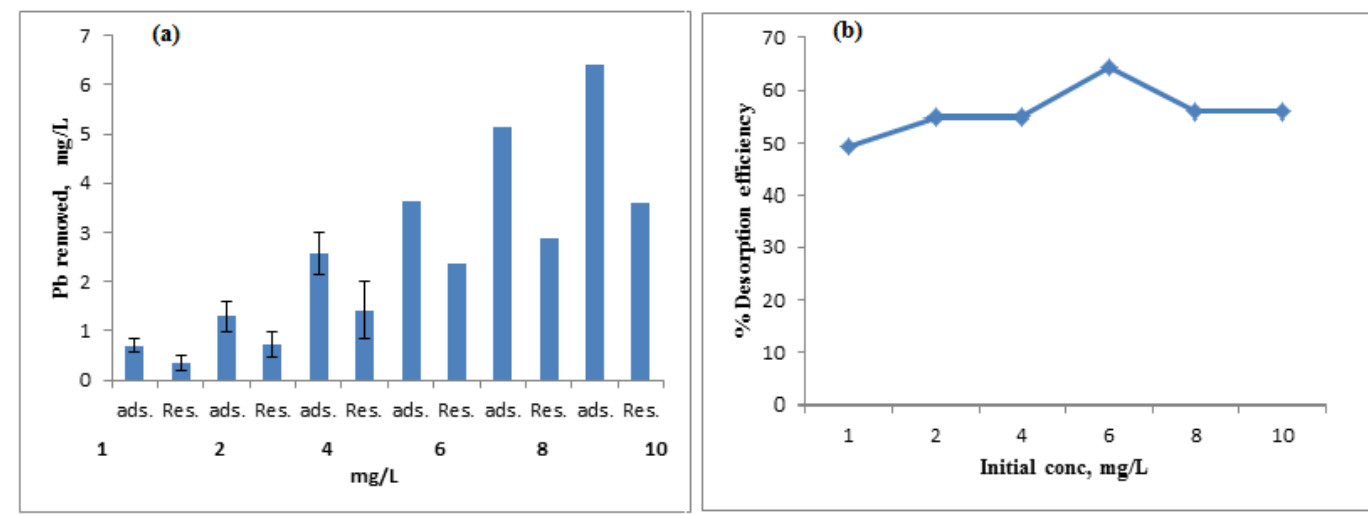

Figure (6) Investigating the reliability of the desorption test for $\mathrm{Pb}(\mathrm{II})$ ions.

At all the initial concentrations for $\mathrm{Pb}^{2+}$, there was a positive trend in the removal of $\mathrm{Pb}^{2+}$ from the adsorbent using $\mathrm{HNO}_{3}$. The \% desorption efficiency of $\mathrm{Pb}^{2+}$ ions was found to be above $50 \%$, which could imply that the active binding sites have higher affinity toward $\mathrm{Pb}^{2+}$ ions forming a stable structure with the coordination of oxygen atoms. This observation could also indicate that the attraction between the $\mathrm{Pb}^{2+}$ and the adsorbent is a weak physisorption (van der Waals force) and not of a true covalent or complexation interaction.

\subsubsection{Solubility Studies on CNT-IPSF/F $\mathrm{F}_{3} \mathrm{O}_{4}$ Nanocomposites}

The effect of $\mathrm{pH}$ on solubility of the adsorbent samples at $\mathrm{pH}$ values of 2, 4, 7, 9 and 12 was found to be $0.013 \%, 0.013 \%, 0.007 \%, 0.007 \%$, and $0.01 \%$, respectively (Figure 7). This is attributed to the amorphous nature of the adsorbent, which allow them to be insoluble in water [30]. This property meets environmental concern for synthetic processes which would not affect the safety of the drinking water [31]. 


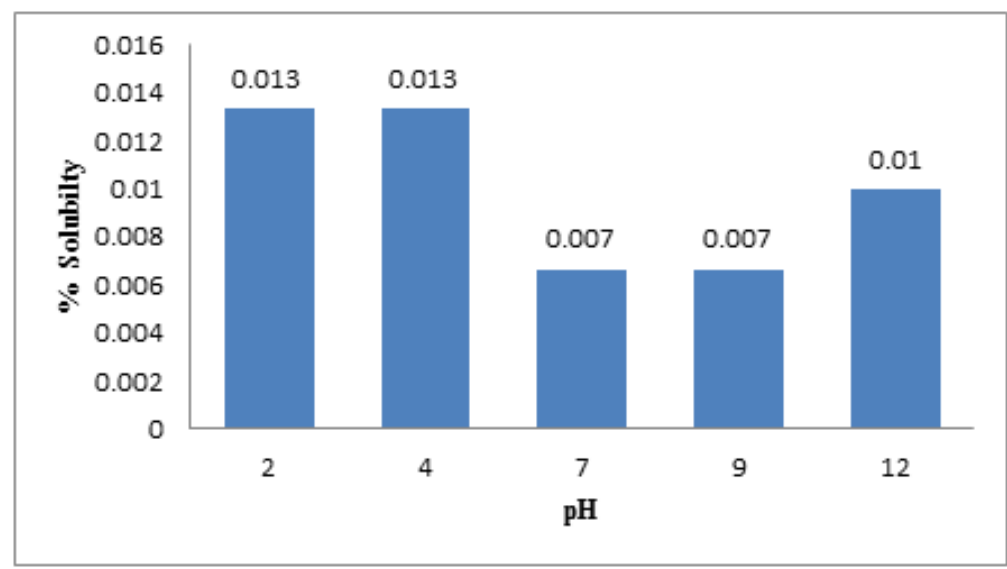

Figure (7) Investigating the solubility of prepared adsorbent

\section{Conclusions}

The CNT-IPSF/ $/ \mathrm{Fe}_{3} \mathrm{O}_{4}$ nanocomposites were successfully fabricated from CNT-IPSF polymer and $\mathrm{SiO}_{2} \cdot \mathrm{Fe}_{3} \mathrm{O}_{4}$ nanoparticles based on various characterization procedures. The SEM images for CNTs showed abundant threadlike entities for CNTs with lengths ranging from nanometers to micrometer. The SEM image revealed that the formation of magnetite-silica nanoparticles which were monodispersed. The XRD analysis revealed magnetite silica NPs with very intense peaks, indicating the ultra-fine nature and small crystallite size of the particles. The peaks indexed as planes (220), (311), (400), (422), (511) and (440) corresponded to a cubic unit cell, characteristic of a cubic spinel structure. Crystallite size measurements were determined as $22.4 \mathrm{~nm}$ from the strongest reflection of the (311) peak, using the Scherrer approximation, which assumes the small crystallite size to be the cause of line broadening. From the magnetization behavior, the magnetization curve did display very narrow hysteresis loop and zero coercivity was detected from the curve characteristic of superparamagnetic material with saturation magnetization of $2.5 \mathrm{emu}^{-1}$. The SEM for as-prepared PSF$\mathrm{CNT} / \mathrm{Fe}_{3} \mathrm{O}_{4}$ nanocomposite further revealed well packed and uniform structure while EDAX confirmed the presence of $\mathrm{Fe}, \mathrm{Si}$ and $\mathrm{O}$ elements, with a stoichiometry $\mathrm{Fe}_{3} \mathrm{O}_{4}$ phase.

The CNT-IPSF/ $/ \mathrm{Fe}_{3} \mathrm{O}_{4}$ nanocomposites had been applied in the removal of $\mathrm{Pb}^{2+}$ ions from synthetic aqueous solutions, and wastewater. The nanocomposites showed $69 \%$ for $\mathrm{Pb}(\mathrm{II})$ ions removal from wastewater compared to $54 \% \mathrm{~Pb}(\mathrm{II})$ ions removal for activated carbon used as standard adsorbent. Optimization of parameters for $\mathrm{Pb}$ (II) ions removal gave optimum conditions of adsorbent dose $(0.05 \mathrm{~g})$, contact time (60 mins) and $\mathrm{pH} 5$ which were set constant in further analysis. Kinetics for adsorption of $\mathrm{Pb}$ (II) ions fitted well with pseudo second order model with highest correlation coefficient values of $>0.9$ while the adsorption process gave best fit with Freundlich isotherms.

Desorption efficiencies (\%)for $\mathrm{Pb}(\mathrm{II})$ ions of above $50 \%$ and gradual increase in desorption efficiency after three desorption cycles gives the reliability of the desorption test for the reusability of the magnetoresponsive CNT-IPSF/ $/ \mathrm{Fe}_{3} \mathrm{O}_{4}$ nanocomposite fabricated. Desorption of the $\mathrm{Pb}$ (II) ions using $\mathrm{HNO}_{3}$ made the developed adsorbent a viable alternative to the common adsorbents available for treatment of wastewater with heavy metal ions.

\section{Recommendations And Further Work}

The fabricated CNT-IPSF/ $/ \mathrm{Fe}_{3} \mathrm{O}_{4}$ nanocomposites material has capability for use in water treatment due to their good adsorption capacity, as well as ease of synthesis at relatively low cost.

Given the positive results found in this study, further investigations should be done on the use of this nanocomposite material on adsorption of other heavy metals and PAHs.More adsorption investigations for the material should be done at $\mathrm{pH} 7-8$ based on results obtained on determination of $\mathrm{pH}$ at the point of zero charge $\left(\mathrm{pH}_{\mathrm{PZC}}\right)$. There will be need to carry out further investigations into the environmental side effects that may emanate from disposal of these nanomaterials since both health and environmental effects are not yet well researched areas.

\section{Acknowledgement}

My special thanks goes to the Department of Chemistry, Kenyatta University, Kenya, for the laboratory space and reagents, National Council of Science, Technology and Innovations (NACOSTI, Kenya) for funding the research project and my co-author for both material and moralsupport. I also thank IOSR for allowing me publish in their journal. 


\section{References}

[1]. Shannon, M.A., et al., Science and technology for water purification in the coming decades. Nature, 2008. 452(7185): p. 301-310.

[2]. Wang, J., et al., Two-phase synthesis of monodisperse silica nanospheres with amines or ammonia catalyst and their controlled selfassembly. ACS applied materials \& interfaces, 2011. 3(5): p. 1538-1544.

[3]. Stafiej, A. and K. Pyrzynska, Adsorption of heavy metal ions with carbon nanotubes. Separation and Purification Technology, 2007. 58(1): p. 49-52.

[4]. Ghosh, U.C., Environmental, economic and health perspectives of arsenic toxicity in Bengal Delta. World Scientific News, 2015. 10: p. 111-139.

[5]. Babel, S. and T.A. Kurniawan, Low-cost adsorbents for heavy metals uptake from contaminated water: a review. Journal of hazardous materials, 2003. 97(1): p. 219-243.

[6]. Wang, S. and H. Wu, Environmental-benign utilisation of fly ash as low-cost adsorbents. Journal of hazardous materials, 2006. 136(3): p. 482-501.

[7]. Yan, A., et al., Solvothermal synthesis and characterization of size-controlled Fe 3 O 4 nanoparticles. Journal of Alloys and Compounds, 2008. 458(1): p. 487-491.

[8]. Wakeman, R. and C. Williams, Additional techniques to improve microfiltration. Separation and Purification Technology, 2002. 26(1): p. 3-18.

[9]. Deng, Y., et al., Superparamagnetic high-magnetization microspheres with an Fe3O4@ SiO2 core and perpendicularly aligned mesoporous SiO2 shell for removal of microcystins. Journal of the American Chemical Society, 2008. 130(1): p. 28-29.

[10]. Patnaik, P., Handbook of environmental analysis: chemical pollutants in air, water, soil, and solid wastes2010: CRC Press.

[11]. Onditi, M., et al., Removal of Pb2+and Cd2+ from drinking water using polysaccharide extract isolated from cactus pads (Opuntia ficus indica). Journal of Applied Polymer Science, 2016. 133(38).

[12]. Zhao, W., et al., Fabrication of uniform magnetic nanocomposite spheres with a magnetic core/mesoporous silica shell structure. Journal of the American Chemical Society, 2005. 127(25): p. 8916-8917.

[13]. Barnakov, Y.A., M.H. Yu, and Z. Rosenzweig, Manipulation of the magnetic properties of magnetite-silica nanocomposite materials by controlled Stober synthesis. Langmuir, 2005. 21(16): p. 7524-7527.

[14]. El Ghandoor, H., et al., Synthesis and some physical properties of magnetite (Fe3O4) nanoparticles. Int. J. Electrochem. Sci, 2012. 7(6): p. 5734-5745.

[15]. Shaaban, E., et al. Structural and optical properties of varies thickness of ZnTe nanoparticle. in BOOK OF PROCEEDINGS. 2013.

[16]. Lyon, L.A., et al., Materials Research Society Symposium Proceedings Volume 635. Anisotropic Nanoparticles-Synthesis, Characterization and Applications, 2000, DTIC Document.

[17]. Kolhatkar, A.G., et al., Tuning the magnetic properties of nanoparticles. International journal of molecular sciences, 2013. 14(8): p. 15977-16009.

[18]. Fatima, T., et al., Sorption of lead by chemically modified rice bran. International Journal of Environmental Science and Technology, 2013. 10(6): p. 1255-1264.

[19]. Boudrahem, F., F. Aissani-Benissad, and H. Ait-Amar, Batch sorption dynamics and equilibrium for the removal of lead ions from aqueous phase using activated carbon developed from coffee residue activated with zinc chloride. Journal of Environmental Management, 2009. 90(10): p. 3031-3039.

[20]. Dharmambal, S., N. Mani, and D. Kannan, Adsorption of Rhodamine-B Dye from the aqueous Solution by using Tectonagrandis Bark Powder. Asian Journal of Research in Chemistry, 2015. 8(5): p. 346.

[21]. Lasheen, M.R., N.S. Ammar, and H.S. Ibrahim, Adsorption/desorption of Cd (II), Cu (II) and Pb (II) using chemically modified orange peel: Equilibrium and kinetic studies. Solid State Sciences, 2012. 14(2): p. 202-210.

[22]. Ismail, M.G.B.H., et al., Freundlich Isotherm Equilibrium Equastions in Determining Effectiveness a Low Cost Absorbent to Heavy Metal Removal In Wastewater (Leachate) At Teluk Kitang Landfill, Pengkalan Chepa, Kelantan, Malaysia. Journal of Geography and Earth Science, 2013. 1(1): p. 01-08.

[23]. Al Othman, Z.A., A. Hashem, and M.A. Habila, Kinetic, equilibrium and thermodynamic studies of cadmium (II) adsorption by modified agricultural wastes. Molecules, 2011. 16(12): p. 10443-10456.

[24]. Zheng, J.-C., et al., Removal of Cu (II) in aqueous media by biosorption using water hyacinth roots as a biosorbent material. Journal of hazardous materials, 2009. 171(1): p. 780-785.

[25]. Kaewsarn, P., Q. Yu, and W. Ma, Interference of co-ions in biosorption of Cu2+ by biosorbent from marine alga Durvillaea potatorum. Environmental Engineering Science, 2001. 18(2): p. 99-104.

[26]. Tofighy, M.A. and T. Mohammadi, Adsorption of divalent heavy metal ions from water using carbon nanotube sheets. Journal of hazardous materials, 2011. 185(1): p. 140-147.

[27]. Tombácz, E., et al., Magnetic iron oxide nanoparticles: Recent trends in design and synthesis of magnetoresponsive nanosystems. Biochemical and biophysical research communications, 2015. 468(3): p. 442-453.

[28]. Tarigh, G.D. and F. Shemirani, Magnetic multi-wall carbon nanotube nanocomposite as an adsorbent for preconcentration and determination of lead (II) and manganese (II) in various matrices. Talanta, 2013. 115: p. 744-750.

[29]. Martins, B.L., et al., Sorption and desorption of Pb 2+ ions by dead Sargassum sp. biomass. Biochemical Engineering Journal, 2006. 27(3): p. 310-314

[30]. Wang, S. and Y. Peng, Natural zeolites as effective adsorbents in water and wastewater treatment. Chemical Engineering Journal, 2010. 156(1): p. 11-24

[31]. Organization, W.H., Guidelines for drinking-water quality2011: Geneva: world health organization. 